\title{
Conversion to eslicarbazepine acetate monotherapy
}

\author{
A pooled analysis of 2 phase III studies \\ OPEN
}

Michael R. Sperling, MD Jacqueline French, MD Mercedes P. Jacobson, MD

Ladislav Pazdera, MD Mallory Gough, PhD Hailong Cheng, PhD

Todd Grinnell, AB

David Blum, MD

On behalf of the Study 045 and 046 Investigators

Correspondence to Dr. Sperling: michael.sperling@jefferson.edu

Supplemental data at Neurology.org

\section{ABSTRACT}

Objective: To assess the efficacy and safety of eslicarbazepine acetate (ESL) monotherapy.

Methods: This post hoc pooled analysis of 2 randomized double-blind studies (093-045 and -046) included adults with partial-onset seizures medically uncontrolled by 1 or 2 antiepileptic drugs (AEDs). Following the baseline period (8 weeks), eligible patients were randomized 2:1 to receive ESL 1,600 mg or 1,200 mg once daily for 18 weeks; the primary endpoint was study exit by meeting predefined exit criteria (signifying worsening seizure control). In each study, treatment was considered effective if the upper $95 \%$ confidence limit for exit rate was lower than the historical control threshold (65.3\%).

Results: Pooled exit rates were as follows: ESL 1,600 mg = 20.6\% (95\% confidence interval: 15.6\%-26.8\%); ESL 1,200 mg = 30.8\% (23.0\%-40.5\%). Use of 2 baseline AEDs or rescue medication, US location, epilepsy duration $\geq 20$ years, and higher maximum baseline seizure frequency were associated with higher exit risks. Median percent reductions in standardized seizure frequency between baseline and the 18-week double-blind period were as follows: ESL 1,600 mg = 43.2\%; ESL 1,200 mg = 35.7\%; baseline carbamazepine use was associated with smaller reductions. Safety profiles were similar between ESL doses.

Conclusions: Exit rates for ESL monotherapy (1,600 mg and 1,200 mg once daily) were lower than the historical control threshold, irrespective of baseline AED use and region, with no additional safety concerns identified. Clinical factors and location clearly influence treatment responses in conversion-to-monotherapy trials.

Classification of evidence: This pooled analysis provides Class IV evidence that for adults with medically uncontrolled partial-onset seizures, ESL monotherapy is well tolerated and effective. Neurology ${ }^{\circledR}$ 2016;86:1095-1102

\section{GLOSSARY}

$\mathbf{A E}=$ adverse event; $\mathbf{A E D}=$ antiepileptic drug; $\mathbf{C l}=$ confidence interval; $\mathbf{E S L}=$ eslicarbazepine acetate; $\mathbf{I T T}=$ intent-totreat; $\mathbf{K M}=$ Kaplan-Meier; MADRS = Montgomery-Åsberg Depression Rating Scale; POS = partial-onset seizure; QOLIE$\mathbf{3 1}$ = 31-item Quality of Life in Epilepsy; SAE = serious adverse event; SSF = standardized seizure frequency; TEAE = treatment-emergent adverse event; UCL = upper 95\% confidence limit.

Antiepileptic drug (AED) monotherapy for epilepsy compares favorably with polypharmacy, often with fewer side effects and fewer drug-drug interactions. ${ }^{1,2}$ There is a need for effective and well-tolerated AEDs for use in the monotherapy setting.

Eslicarbazepine acetate (ESL) (Aptiom; Sunovion Pharmaceuticals Inc., Marlborough, MA) is a once-daily oral AED, approved by the US Food and Drug Administration for the treatment of partial-onset seizures (POS) as monotherapy or adjunctive therapy, and by Health Canada as adjunctive therapy of POS in patients with epilepsy who are not satisfactorily controlled with conventional therapy. ESL (Zebinix; BIAL - Portela \& Ca., S.A., S. Mamede do Coronado,

From Thomas Jefferson University (M.R.S.), Philadelphia, PA; New York University Comprehensive Epilepsy Center (J.F.), New York, NY; Department of Neurology (M.P.J.), Temple University School of Medicine, Philadelphia, PA; Vestra Clinics s.r.o. (L.P.), Rychnov nad Kneznou, Czech Republic; FireKite (M.G.), Macclesfield, UK; and Sunovion Pharmaceuticals Inc. (H.C., T.G., D.B), Marlborough, MA.

The study 045 and 046 coinvestigators are listed on the Neurology ${ }^{\circledR}$ Web site at Neurology.org.

Go to Neurology.org for full disclosures. Funding information and disclosures deemed relevant by the authors, if any, are provided at the end of the article. The Article Processing Charge was paid by Sunovion Pharmaceuticals Inc.

This is an open access article distributed under the terms of the Creative Commons Attribution-NonCommercial-NoDerivatives License 4.0 (CC BY-NC-ND), which permits downloading and sharing the work provided it is properly cited. The work cannot be changed in any way or used commercially. 
Portugal) is approved by the European Medicines Agency as adjunctive therapy of POS in adults. Eslicarbazepine, the active metabolite of ESL, is thought to inhibit sodium currents by stabilizing the inactivated state of voltagegated sodium channels. ${ }^{3}$

The results of 2 ESL monotherapy studies (093-045 and 093-046) have been reported previously. ${ }^{4,5}$ ESL monotherapy (1,600 mg and $1,200 \mathrm{mg}$ once daily) was found to be effective (superior to a historical control) and well tolerated. A combined analysis of these studies allowed a more thorough evaluation of ESL monotherapy; pooling data from identically designed studies provides greater statistical power for the assessment of treatment effects in patient subgroups of interest. This analysis evaluates the relationships between various factors (including geographic region, number and type of baseline AEDs, benzodiazepine use, and presence of secondarily generalized seizures) and the efficacy and safety of ESL monotherapy.

METHODS The study design (including inclusion and exclusion criteria, exit criteria, and randomization technique) and statistical methods (including sample size determination) were identical for both studies. ${ }^{4,5}$

Classification of evidence. The primary research question was whether the rate of study exit (by meeting predefined exit criteria signifying worsening seizure control) for patients taking ESL $(1,600 \mathrm{mg}$ or $1,200 \mathrm{mg})$ was lower than the historical control threshold. This pooled analysis provides Class IV evidence that for adults with medically uncontrolled POS, ESL monotherapy is well tolerated and effective.

Standard protocol approvals, registrations, and patient consents. The 2 studies (093-046 [NCT01091662] and 093045 [NCT00866775], both registered at ClinicalTrials.gov) were conducted between 2009 and 2013 at sites in the United States, Canada, Bulgaria, Serbia, the Ukraine, and the Czech Republic, in accordance with the principles of the Declaration of Helsinki, the International Conference on Harmonisation guidelines, and all national, state, and local laws of the pertinent regulatory authorities. Approval was received from the relevant independent ethics committees/institutional review boards, and all patients provided informed consent.

Patients. Patients aged 16 to 70 years with a diagnosis of localization-related (focal) epilepsy (defined by the International League Against Epilepsy, 1981) ${ }^{6}$ and a history of POS were eligible for study participation if they satisfied the following criteria: no confounding factors (e.g., psychogenic nonepileptic spells, syncope, progressive structural abnormality); documented EEG recording consistent with POS; $\geq 4$ POS during the 8 weeks before screening, with no seizure-free period $\geq 4$ weeks; treatment with stable doses of 1 or 2 AEDs in the 4 weeks before screening (if receiving 2 AEDs at screening, only 1 could be a sodium channel blocker [i.e., phenytoin, carbamazepine, oxcarbazepine, or lamotrigine] and only 1 could be in the upper dose range [greater than approximately two-thirds of its defined daily dose $^{7}$ ); and no additional/potential health complications (elderly patients [65-70 years] only).

Study design. After an 8 -week baseline period, eligible patients were randomized 2:1 to receive oral ESL (1,600- or 1,200-mg tablets once daily), and began the 18-week, double-blind treatment period (2-week ESL titration, 6-week AED conversion [concomitant AEDs withdrawn], 10-week ESL monotherapy). Eligible patients then had the option to enter an open-label extension study (long-term data will be published separately); alternatively, patients entered a 1-week dosetapering period and left the study (figure e-1 on the Neurology ${ }^{\circledR}$ Web site at Neurology.org).

Individual patient data from the double-blind phases of the 2 trials (045 and 046) were pooled and analyzed.

Assessments. Primary endpoint. Seizure data were obtained using seizure diaries, completed daily by the patients or their caregivers throughout the study. The primary efficacy endpoint was study exit by meeting $\geq 1$ of 5 prospectively defined exit criteria (signifying worsening seizure control), between the start of the AED conversion period and the end of the monotherapy period.

Secondary endpoints. The key secondary efficacy endpoint was the percentage of patients who achieved seizure freedom throughout the 10-week monotherapy period. Other prospectively specified secondary efficacy endpoints included change in standardized seizure frequency (SSF) (per 28 days) between baseline and the 18-week double-blind treatment period; responder rate (proportion of patients with $\geq 50 \%$ reduction in SSF vs baseline); change in 31-item Quality of Life in Epilepsy (QOLIE-31) total scores; change in Montgomery-Åsberg Depression Rating Scale (MADRS) scores; and completion rates (proportions of patients completing the 18-week treatment and 10 -week monotherapy periods).

Safety and tolerability. Investigators recorded adverse events (AEs) at each clinic visit. AEs were coded using the Medical Dictionary for Regulatory Activities, version 13.1. Treatmentemergent AEs (TEAEs) were defined as AEs that occurred on or after the first dose of study drug. Serious AEs (SAEs) were reported separately; classification of AEs as "serious" was at the judgment of the investigators. Summary statistics for TEAEs were calculated for each study period (titration, AED conversion, and ESL monotherapy periods).

Statistical analyses. Both studies used a historical control comparator, as proposed by French et al. ${ }^{8}$ The historical control exit rate was determined from the placebo/pseudo-placebo groups of 8 historical conversion-to-monotherapy trials. The lower bound of the $95 \%$ prediction interval of the overall exit rate (i.e., $65.3 \%$ at 112 days $)^{9}$ was used as the exit threshold for a scenario involving a single study. Similarly to the individual studies, pooled cumulative exit rates and $95 \%$ confidence intervals (CIs) at 112 days were estimated using Kaplan-Meier (KM) methodology for each ESL treatment group. Methods for censoring and patient reassignment have been previously reported. ${ }^{4,5}$

Exit rates and 95\% CIs were estimated for patient subgroups defined by baseline AED use (those AEDs used by $\geq 15 \%$ of patients) and region (US vs non-US). Effects of subgroup factors were also evaluated separately, using a Cox proportional hazards regression model.

A worst-case scenario analysis was conducted to evaluate the potential confounding effect of benzodiazepine use: patients who took benzodiazepine derivatives during the AED conversion 
Table 1 Selected demographics and baseline clinical characteristics for the pooled efficacy population (US and non-US subgroups)

$$
\text { US }(n=211) \quad \text { Non-US }(n=121)
$$

Patient demographics

Race, \%

$$
\text { White }
$$

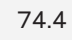

99.2

Black or African American

Asian

11.8

1.9

0.0

Hispanic ethnicity, \%

Weight, kg, mean (SD)

16.6

$88.3(26.0)$

46.4

0.8

BMI $>30 \mathrm{~kg} / \mathrm{m}^{2}, \%$

Clinical characteristics

Duration of epilepsy, $y$, median

17.0

43.6

11.0

Duration of epilepsy $\geq 20 y$, \%

AEDs used by $\geq 15 \%$ of patients, ${ }^{a} \%$

Carbamazepine

26.5

28.9

Lamotrigine

11.8

19.8

Levetiracetam

31.8

12.4

Valproic acid

10.9

35.5

Taking 1 AED, ${ }^{\text {a } \%}$

Partial seizures evolving to secondarily generalized seizures, \%

Maximum consecutive 2-d seizure rate, mean (SD)

Maximum consecutive $28-d$ seizure

rate, mean (SD)

Maximum consecutive 28- $d$ seizure

rate $>15 / \mathrm{mo}, \%$

Benzodiazepines used, \%
69.4

$39.7^{c}$

$25.1^{b}$

$3.7(2.6)^{b}$

$2.2(1.3)^{c}$

$13.4(9.1)^{\mathrm{b}}$

$10.0(7.2)^{c}$

$31.3^{b}$

$14.9^{c}$

10.0

2.5

Abbreviations: $\mathrm{AED}=$ antiepileptic drug; $\mathrm{BMI}=$ body mass index; US = United States. Percentages are calculated based on the number of patients with available data in the efficacy population in each subgroup.

${ }^{a}$ An AED was considered to be used at baseline if it was started at any time before the first dose of study drug and continued into the titration period.

${ }^{b} \mathrm{n}=210$.

${ }^{c} \mathrm{n}=120$.

clinical characteristics were generally well balanced between dose groups (table e-1) and comparable to those of the historical control comparator group (Jacobson et al., 52015 [table S2]).

The efficacy population comprised 332 patients (ESL 1,600 mg, $\mathrm{n}=218$; ESL $1,200 \mathrm{mg}, \mathrm{n}=$ 114; US, $\mathrm{n}=211$; non-US, $\mathrm{n}=121$ ). There were some notable differences in demographics and clinical characteristics between the US and non-US subgroups (table 1). The US subgroup had a longer median duration of illness, more levetiracetam use, and less valproic acid and lamotrigine use, as well as higher proportions of obese individuals, and black, Asian, and Hispanic patients, than the non-US subgroup. Compared with the non-US subgroup, the US subgroup also had higher maximum 2- and 28-day seizure rates and more benzodiazepine use during the baseline period.

Efficacy. Primary endpoint. In the individual studies (045 and 046), the upper 95\% confidence limits (UCLs) of exit rates for both ESL doses were lower than the historical control threshold (65.3\%), indicating drug efficacy. ${ }^{4,5}$ The pooled KM-estimated exit rates at 112 days were $20.6 \%$ (95\% CI: $15.6 \%-26.8 \%$ ) for ESL $1,600 \mathrm{mg}$ and $30.8 \%(23.0 \%-40.5 \%)$ for ESL $1,200 \mathrm{mg}$ (figure 1).

Secondary analyses of the primary endpoint. US vs non-US patients. The KM-estimated exit rates for the US subgroup were greater than those for the non-US subgroup (figure 2A). Cox proportional hazard regression analysis confirmed that US patients were significantly more likely to exit the study $(p<0.001$; figure 2C). The time to exit for US patients exhibited a dose-response relationship; the rate was lower with ESL $1,600 \mathrm{mg}$ vs $1,200 \mathrm{mg}$. For US patients taking 2 baseline AEDs, or with secondarily generalized seizures before or during the baseline period, the difference in exit rates between dose groups was particularly marked. For all 4 subgroups (US and non-US patients taking ESL 1,600 and 1,200 mg), the UCLs of the exit rates were lower than the $65.3 \%$ historical control threshold.

Baseline AEDs. KM-estimated exit rates were also calculated for subgroups defined by baseline AED use (for AEDs taken by $\geq 15 \%$ of patients; figure $2 B$ ). Use of carbamazepine $(\mathrm{n}=91)$, lamotrigine $(\mathrm{n}=$ 49), levetiracetam $(\mathrm{n}=82)$, and valproic acid $(\mathrm{n}=$ 66) at baseline did not have statistically significant effects on risk of exit (figure 2C).

Overall, $31.0 \%$ of patients were taking 2 AEDs during the baseline period. The exit risk was significantly higher for patients taking 2 baseline AEDs (vs 1; figure 2C). In addition, exit risk was
RESULTS Patients. The ITT population comprised 365 patients (ESL 1,600 mg, $\mathrm{n}=242$; ESL 1,200 $\mathrm{mg}, \mathrm{n}=123$; figure e-2). Baseline demographic and 


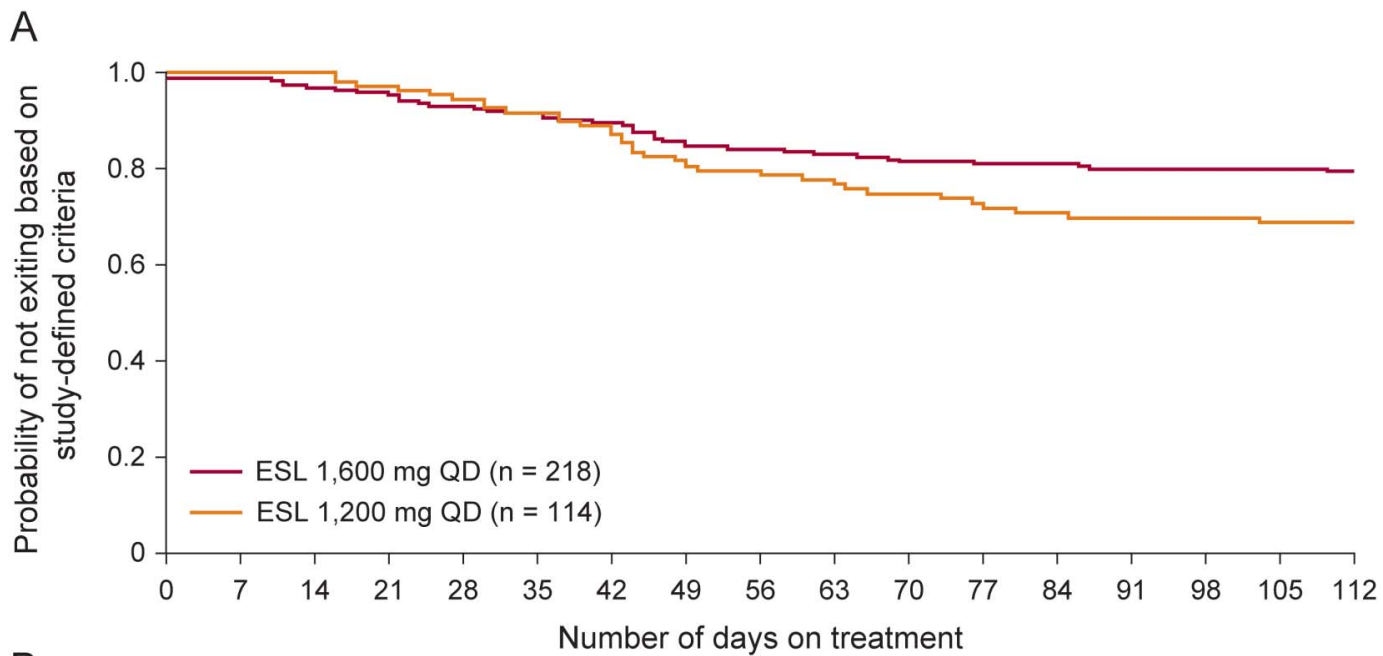

B

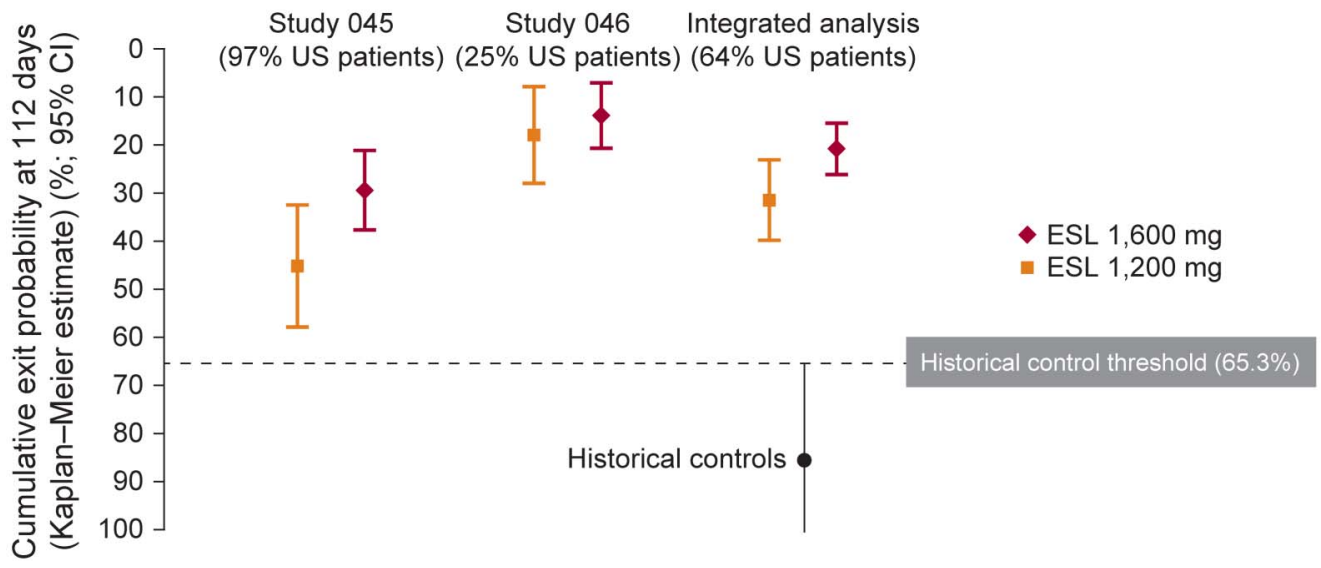

$\mathrm{Cl}=$ confidence interval; $\mathrm{ESL}=$ eslicarbazepine acetate; $\mathrm{QD}=$ once-daily; US = United States.

significantly lower for patients taking phenytoin at baseline (vs those not taking phenytoin; $p=$ 0.049), although the sample size was small (only 30 patients were taking baseline phenytoin).

Benzodiazepine use. Patients who used benzodiazepines had a higher risk of study exit (figure 2C). Approximately $7.8 \%$ of patients had not used benzodiazepines before randomization but used them during the 18 -week treatment period. In a sensitivity analysis of the primary endpoint, in which patients who used benzodiazepines after the start of the AED conversion period, but not before the first dose of study medication, were deemed to have met the exit criteria, the UCLs of exit rates for both ESL dose groups were also lower than the $65.3 \%$ historical control threshold $(1,600 \mathrm{mg}=24.2 \%$ [95\% CI: $18.9 \%-30.8 \%] ; 1,200 \mathrm{mg}=32.6 \%$ [24.6\%-42.4\%]).

Disease characteristics. Exit risk was also found to be higher for patients with a duration of epilepsy $\geq 20$ years, for patients with a higher baseline seizure rate (maximum consecutive 2-day rate), for those who used vagal nerve stimulation during baseline, and for those who used rescue medication (figure 2C).

Secondary endpoints. The proportion of patients who achieved seizure freedom during the entire 10-week monotherapy period was similar for the 2 ESL dose groups (ESL 1,600 mg $=8.7 \%$ [95\% CI: $5.3 \%-$ 13.3\%]; ESL $1,200 \mathrm{mg}=7.9 \%$ [CI: 3.7\%-14.5\%]).

Seizure frequency was calculated as SSF per 28 days. The median percent reduction from baseline in SSF for the 18-week treatment period was 43.2\% with ESL $1,600 \mathrm{mg}$ and $35.7 \%$ with ESL $1,200 \mathrm{mg}$ (figure 3); for the 10-week monotherapy period, the median percent reduction was $46.3 \%$ and $47.1 \%$ with ESL $1,600 \mathrm{mg}$ and $1,200 \mathrm{mg}$, respectively. Responder rates (proportion of patients with $\geq 50 \%$ reduction in SSF) during the 18 -week treatment period were $42.7 \%$ for ESL $1,600 \mathrm{mg}$ and $36.0 \%$ for ESL 1,200 mg. Reductions in seizure frequency occurred in patients taking different AEDs at 
Figure 2 Subgroup analyses of exit rates (pooled efficacy population): Influence of geographic region on exit rate (US vs non-US regions) (A), of baseline AED use (AEDs used by $\geq 15 \%$ of patients) on exit rate (B), and of patient characteristics on risk of study exit (pooled efficacy population) (C)

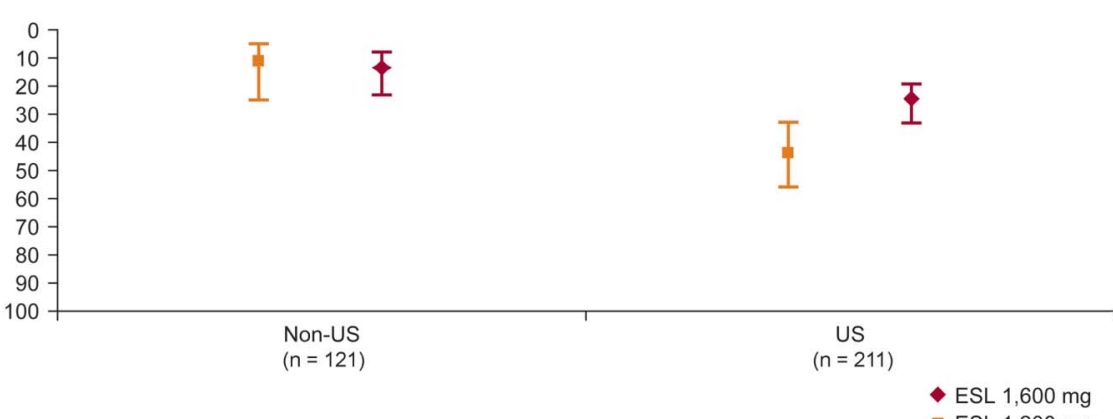

$\mathrm{B}$

- ESL $1,200 \mathrm{mg}$

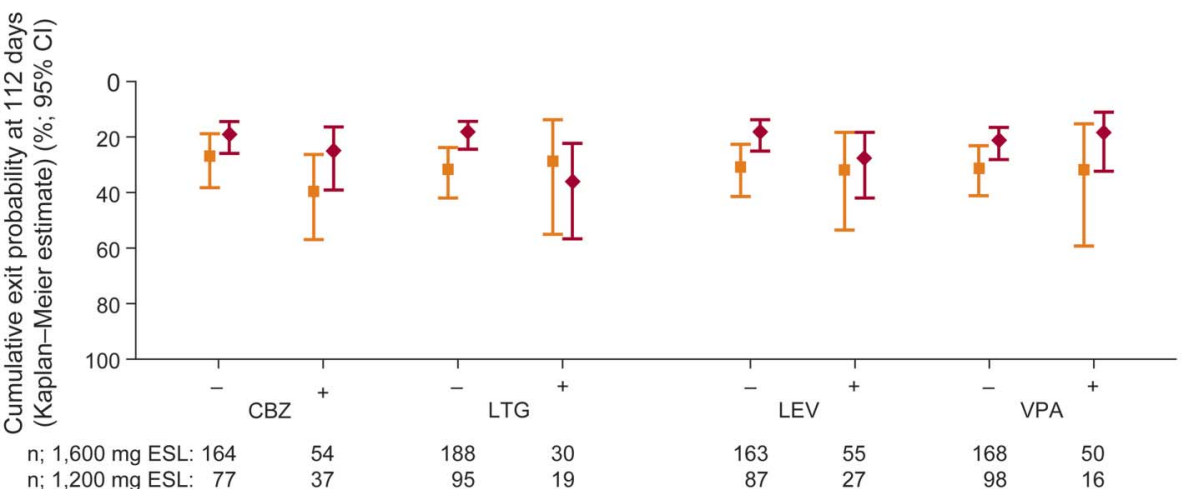

C

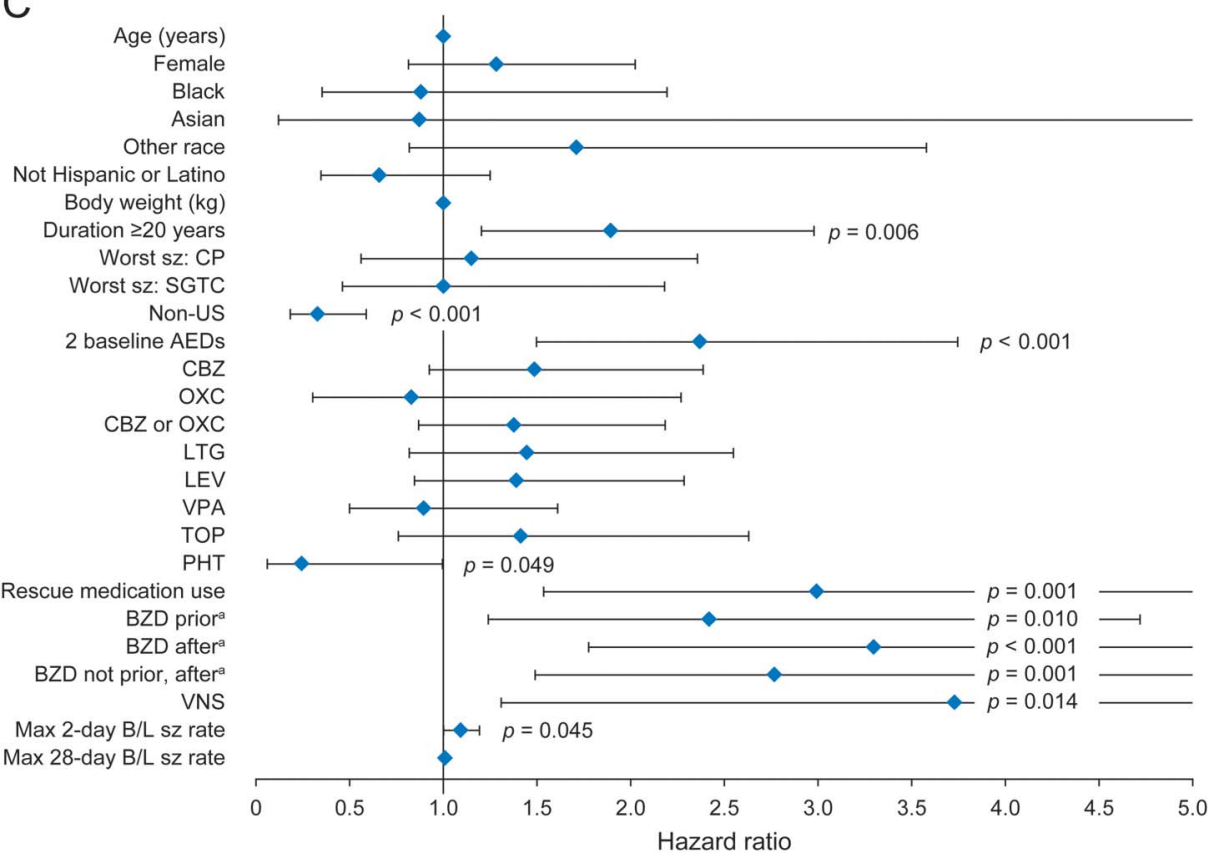

Note that for age, baseline body weight, and maximum 2- or 28-day seizure rate, the hazard ratio is displayed for a single unit change; otherwise, it is shown for the referenced group compared to those without the stated factor. VPA included all dosage forms combined unless otherwise stated (including VPA, sodium valproate, divalproex sodium, etc.). aBZD derivatives used before study treatment (prior), after initiation of the AED conversion period as rescue or emergency medication (after), or only after study treatment (not prior, after). AED = antiepileptic drug; B/L = baseline; BZD = benzodiazepine; CBZ = carbamazepine; $\mathrm{Cl}=$ confidence interval; $\mathrm{CP}=$ complex partial seizure; duration = duration of epilepsy; $\mathrm{ESL}=$ eslicarbazepine acetate; LEV = levetiracetam; LTG = lamotrigine; OXC = oxcarbazepine; PHT = phenytoin; SGTC = secondarily generalized tonic-clonic seizures (also referred to as complex partial seizures with secondary generalization); sz = seizure; TOP $=$ topiramate; US $=$ United States; VNS = vagal nerve stimulator; VPA = valproic acid. 


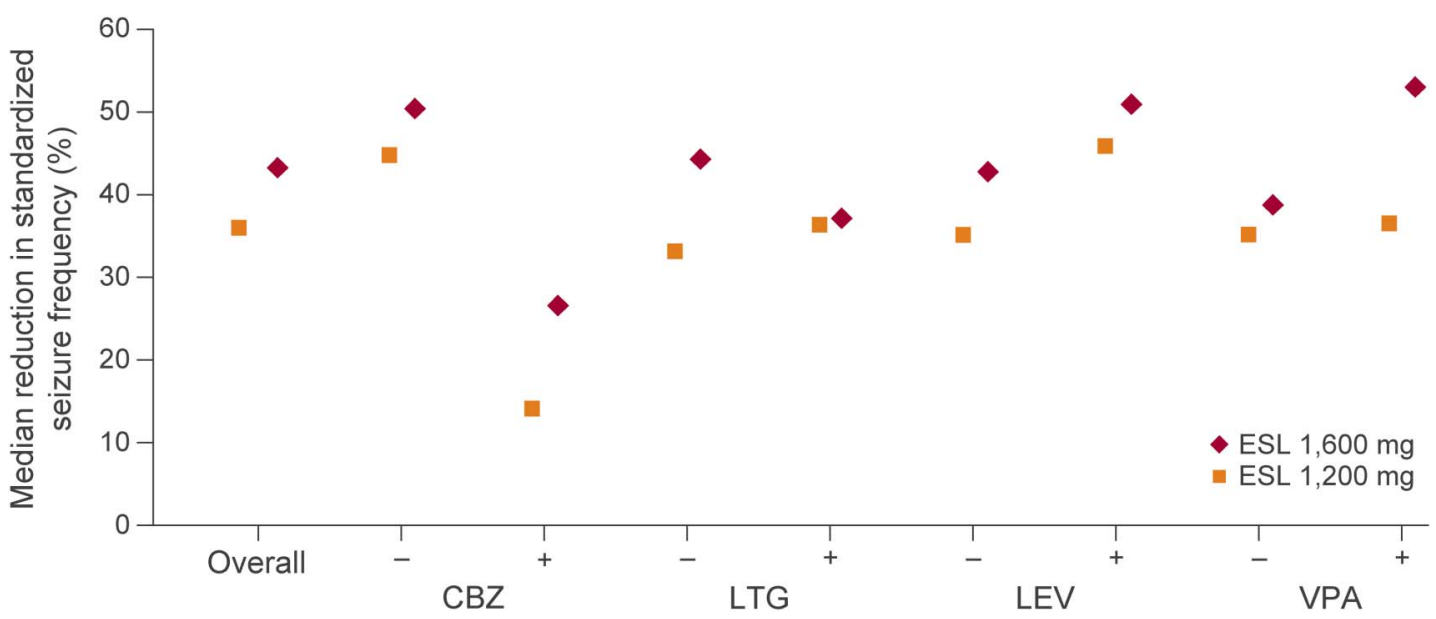

Median percentage reduction in standardized seizure frequency (seizures per 28 days; between baseline and the 18-week treatment period) overall and by baseline AED (for AEDs used by $\geq 15 \%$ of patients during baseline; efficacy population). AED = antiepileptic drug; CBZ = carbamazepine; ESL = eslicarbazepine acetate; LEV = levetiracetam; LTG = lamotrigine; VPA = valproic acid.

baseline, but the magnitude of reduction was less for patients who were taking carbamazepine at baseline than for those who were not (figure 3).

For patients who continued into the monotherapy period, overall QOLIE-31 scores increased between baseline and the end of the monotherapy period (ESL 1,600 mg, 5.7-point median increase; ESL $1,200 \mathrm{mg}, 3.3$ point median increase; calculated for the 252 patients who had QOLIE-31 scores for both the baseline and monotherapy periods). Of note, there was a statistically significant correlation $(p=$ 0.001 ) between reduction in SSF from baseline and the increase in overall QOLIE-31 score. Similarly, MADRS total scores decreased by a median of 1 point with ESL 1,600 $\mathrm{mg}$ and were unchanged with ESL

\begin{tabular}{|c|c|c|c|}
\hline \multirow{2}{*}{$\begin{array}{l}\text { Table } 2 \\
\text { TEAE }\end{array}$} & \multicolumn{3}{|c|}{$\begin{array}{l}\text { Incidence of TEAEs }{ }^{\text {a }} \text { during different treatment periods (pooled ITT } \\
\text { population) }\end{array}$} \\
\hline & & $\begin{array}{l}\text { ESL } 1,200 \mathrm{mg} \\
\text { once daily, } \mathrm{n}(\%)\end{array}$ & $\begin{array}{l}\text { ESL } 1,600 \mathrm{mg} \\
\text { once daily, } \mathrm{n}(\%)\end{array}$ \\
\hline \multicolumn{2}{|c|}{ Titration period } & $\mathrm{n}=123$ & $n=242$ \\
\hline \multicolumn{2}{|c|}{ Dizziness } & 18 (15) & 35 (14) \\
\hline \multicolumn{2}{|c|}{ Headache } & $8(7)$ & $32(13)$ \\
\hline \multicolumn{2}{|c|}{ Somnolence } & $7(6)$ & 23 (10) \\
\hline \multicolumn{2}{|c|}{ Fatigue } & $12(10)$ & $18(7)$ \\
\hline \multicolumn{2}{|c|}{ Taper/conversion period } & $\mathrm{n}=114$ & $n=218$ \\
\hline \multicolumn{2}{|c|}{ Headache } & $12(11)$ & 27 (12) \\
\hline \multicolumn{2}{|c|}{ Dizziness } & $8(7)$ & $24(11)$ \\
\hline \multicolumn{2}{|c|}{ Monotherapy period } & $\mathrm{n}=93$ & $n=181$ \\
\hline \multicolumn{2}{|c|}{ Headache } & 10 (11) & 21 (12) \\
\hline
\end{tabular}

Abbreviations: ESL = eslicarbazepine acetate; ITT = intent-to-treat; TEAE = treatmentemergent adverse event.

a Occurring in $\geq 5 \%$ of patients in both dose groups.
1,200 mg (calculated for the 267 patients who had MADRS scores for both periods).

Completion rates for the 18-week treatment period were $71.6 \%$ (95\% CI: $65.1 \%-77.4 \%$ ) for ESL $1,600 \mathrm{mg}$ and $61.4 \%(51.8 \%-70.4 \%)$ for ESL $1,200 \mathrm{mg}$. For the 10 -week monotherapy period, completion rates were $86.2 \%$ (95\% CI: 80.3\%$90.9 \%$ ) for ESL $1,600 \mathrm{mg}$ and $75.3 \%$ (65.2\%83.6\%) for ESL 1,200 mg.

Safety. TEAEs reported for $\geq 5 \%$ of patients during each treatment period are shown in table 2. Headache, dizziness, somnolence, and fatigue were the most frequently reported TEAEs. There was no clear relationship between incidence of these TEAEs and ESL dose. Depression was reported in $2.5 \%$ and $0.8 \%$ of patients taking ESL 1,600 mg and 1,200 $\mathrm{mg}$, respectively, and "suicidal ideation" in 2 patients (1.6\%) taking ESL 1,200 mg. Serum sodium $\leq 125 \mathrm{mEq} / \mathrm{L}$ was recorded in 7 patients taking ESL $1,600 \mathrm{mg}(2.9 \%)$ and 5 patients taking ESL 1,200 $\mathrm{mg}(4.1 \%)$. TEAEs led to discontinuation in $15.3 \%$ and $8.1 \%$ of patients taking ESL 1,600 mg and $1,200 \mathrm{mg}$, respectively. Events leading to discontinuation included hyponatremia (1.4\%), skin and subcutaneous tissue disorders (ESL 1,600 mg, 2.9\%; ESL 1,200 mg, 0.8\%), and drug rash with eosinophilia and systemic symptoms (ESL 1,600 mg, 1 patient).

During the 18-week treatment period, SAEs occurred in 21 patients (5.8\% overall: ESL 1,600 mg, 6.6\%; ESL 1,200 mg, 4.1\%). The most frequent SAEs were hyponatremia (ESL 1,600 mg, 1.2\% [3 patients]; ESL 1,200 mg, 0\%), complex partial seizures $(0.8 \%$ [ 2 patients]; $0 \%)$, and partial seizures with secondary generalization $(0.4 \%$ [ 1 patient $] ; 0.8 \%$ 
[1 patient]). There were no cases of second- or thirddegree atrioventricular block; cardiac SAEs were reported in 2 patients taking ESL 1,200 mg (1.6\%): 1 had cardiogenic shock and 1 had atrial flutter (before the first ESL dose). There was 1 death in study 045 (ESL 1,200-mg treatment arm), caused by multiple injuries due to a car accident of unknown cause, and 1 pretreatment seizure-related death in study 046 (during the baseline period).

DISCUSSION The findings of this analysis extend those of the individual ESL monotherapy studies (045 and 046). ${ }^{4,5}$ The pooled analysis provides more precise estimates of the overall treatment effect and higher statistical power to examine the effects of subgroup factors.

Factors statistically associated with higher exit risk (failed transition to ESL monotherapy) are shown in figure $2 \mathrm{C}$; as several of these factors are often indicators of more severe epilepsy, the greater propensity for exit is not surprising. In future studies (and perhaps clinical practice), when transitioning to ESL monotherapy, it may be beneficial to use a longer tapering schedule to reduce the risk of seizure exacerbation in individuals with risk factors. In addition, patients from the United States were significantly more likely to exit the studies. A lamotrigine XR monotherapy trial also found that KM-estimated exit rates were higher in US vs non-US patients. ${ }^{9}$ In contrast, a lacosamide study found a lower exit rate in North American patients vs patients from other regions. ${ }^{10}$ The observed difference in exit rates may be related to differences between regions in clinical practice, patient characteristics, or placebo-response rate, as well as economic or cultural influences. For example, the use of newer-generation AEDs was more prevalent among US patients. As US patients had longer duration of illness and more frequent seizures than non-US patients, they may have had more severe epilepsy and so were at greater risk of study exit.

Although the exit rate was numerically higher for patients who were taking carbamazepine at baseline vs those taking other AEDs, the UCLs for both ESL dose groups were below the 65.3\% threshold. Similarly, patients who converted from carbamazepine to monotherapy with other AEDs (pregabalin, valproate, topiramate, felbamate, oxcarbazepine, tiagabine, or rufinamide) had an increased hazard rate for study exit $(8.0 \%) .{ }^{8}$ Hence, the above finding may not be attributable to any similarities between carbamazepine and ESL, but could be related to the withdrawal of carbamazepine. In the current study, patients who converted from carbamazepine also had less marked reductions in seizure frequency than those who converted from other commonly used background AEDs; the reason for this remains unclear.

The appropriate use of a historical control comparator is based on the concept that there are no substantive differences in population characteristics between the current studies and the historical control, or that any population differences do not affect exit rates. It is of note that the CIs for the ESL 1,200 mg exit rate did not overlap between studies 045 and 046 , suggesting that the study population influenced exit rates in these trials. However, exit rates for both dose groups in these studies were lower than the rate for the historical control.

Patients were diagnosed using the 1981 version of the International League Against Epilepsy classification. ${ }^{6}$ Although more recent versions exist, ${ }^{11}$ the 1981 classification was used to ensure consistency with other AED trials. As the 1981 guidelines are still used frequently in clinical practice, we are confident that the population remains relevant to today's patients.

The safety profiles of ESL 1,600 mg and 1,200 mg were similar and there were no incidences of sudden unexpected death in epilepsy during ESL therapy. No new safety findings of concern were identified in this pooled analysis.

Exit rates for patients taking ESL (1,600 mg and $1,200 \mathrm{mg}$ once daily) monotherapy were lower than the historical control threshold, irrespective of baseline AED use and region, and ESL was well tolerated. The potential effects of clinical and demographic factors on patient outcomes should be taken into consideration when designing future monotherapy studies. Further evaluation of the effect of baseline AED use on treatment response is also needed, given the difference in outcomes between patients who were taking baseline phenytoin and carbamazepine in this analysis.

\section{AUTHOR CONTRIBUTIONS}

M. Sperling was involved in the acquisition, analysis, and interpretation of data, and in drafting and revising the manuscript for content. J. French was involved in the development of the study concept/design, and in drafting and revising the manuscript for content. M. Jacobson was involved in the acquisition, analysis, and interpretation of data, and in drafting and revising the manuscript for content. L. Pazdera was involved in the development of the study concept/design, in the acquisition, analysis, and interpretation of data, and in drafting and revising the manuscript for content. M. Gough was involved in drafting and revising the manuscript for content. H. Cheng was involved in the development of the study concept/design, in the acquisition, analysis, statistical analysis, and interpretation of data, and in drafting and revising the manuscript for content. T. Grinnell was involved in the development of the study concept/design, in the analysis and interpretation of data, and in drafting and revising the manuscript for content. D. Blum was involved in the development of the study concept/design, in obtaining funding, in the study supervision/coordination, in the acquisition, analysis, and interpretation of data, and in drafting and revising the manuscript for content.

\section{ACKNOWLEDGMENT}

The authors thank Rebecca Thair of FireKite, an Ashfield company, for assistance with editing the manuscript for nonintellectual content. 


\section{STUDY FUNDING}

The study was funded by Sunovion Pharmaceuticals Inc.

\section{DISCLOSURE}

M. Sperling has received consultancy honoraria for UCB Pharma, honorarium from Wiley for serving as associate editor for Epilepsia 2013 2014, and has been the editor-in-chief of Epilepsia from 2014 to present (no honorarium). M. Sperling has also received funding as site principal investigator from Sunovion Pharmaceuticals Inc., UCB Pharma, SK Life Sciences, Eisai, Lundbeck, Acorda, Upsher-Smith, Medtronics, Brain Sentinel, Visualase, and GlaxoSmithKline, for research contracted and paid to Thomas Jefferson University, and has received federal funding from NIH and the Defense Advanced Research Projects Agency. J. French has consulted for Acorda, Anavex, Brabant Pharma, BioPharm Solutions, Eisai, GlaxoSmithKline, GW Pharma, Impax, Johnson \& Johnson, Marinus, Neusentis, Novartis, Pfizer, Sage, Sunovion Pharmaceuticals Inc., SK Life Sciences, Supernus, Takeda, UCB Pharma, Upsher-Smith, Ultragenyx, Vertex, Zogenix, and Zynerba. All consulting was on behalf of the Epilepsy Study Consortium, and fees are paid to the consortium; New York University receives salary support from the consortium. J. French has also received grants and research support from Acorda, Alexza, LCGH, Eisai, Lundbeck, Pfizer, SK Life Sciences, UCB Pharma, Upsher-Smith, Vertex, NINDS, and the Epilepsy Foundation. M. Jacobson has received honoraria from Sunovion Pharmaceuticals Inc. and research support from Lundbeck, Sunovion Pharmaceuticals Inc. Sage Therapeutics, and Marinus. L. Pazdera is an employee of Vestra Clinics and has received research support from Sunovion Pharmaceuticals Inc. M. Gough is an employee of FireKite, and was funded by Sunovion Pharmaceuticals Inc. to provide medical writing support. H. Cheng is an employee of Sunovion Pharmaceuticals Inc. T. Grinnell is an employee of Sunovion Pharmaceuticals Inc. D. Blum is an employee of Sunovion Pharmaceuticals Inc. Go to Neurology.org for full disclosures.

Received August 7, 2015. Accepted in final form December 3, 2015.

\section{REFERENCES}

1. Perucca E. Designing clinical trials to assess antiepileptic drugs as monotherapy. CNS Drugs 2008;22:917-938.

2. Perucca E, Tomson T. The pharmacological treatment of epilepsy in adults. Lancet Neurol 2011;10:446-456.
3. Hebeisen S, Pires N, Loureiro AI, et al. Eslicarbazepine and the enhancement of slow inactivation of voltage-gated sodium channels: a comparison with carbamazepine, oxcarbazepine and lacosamide. Neuropharmacology 2015;89:122-135.

4. Sperling MR, Harvey J, Grinnell T, Cheng H, Blum D; 045 Study Team. Efficacy and safety of conversion to monotherapy with eslicarbazepine acetate in adults with uncontrolled partial-onset seizures: a randomized historical-control phase III study based in North America. Epilepsia 2015;56:546-555.

5. Jacobson MP, Pazdera L, Bhatia P, et al. Efficacy and safety of conversion to monotherapy with eslicarbazepine acetate in adults with uncontrolled partial-onset seizures: a historical-control phase III study. BMC Neurol 2015;15:46.

6. Commission on Classification and Terminology of the International League Against Epilepsy (ILAE). Proposal for revised clinical and electroencephalographic classification of epileptic seizures. Epilepsia 1981;22:489-501.

7. WHO Collaborating Centre for Drug Statistics Methodology. ATC/DDD index. Available at: http://www.whocc. no/atc_ddd_index/. Accessed October 23, 2015.

8. French JA, Wang S, Warnock B, Temkin N. Historical control monotherapy design in the treatment of epilepsy. Epilepsia 2010;51:1936-1943.

9. U.S. Food and Drug Administration. Ling X. Lamictal ${ }^{\circledR}$ XRTM (lamotrigine) historical-controlled trial: Peripheral and Central Nervous System Drugs Advisory Committee Meeting 2011. Available at: http://www.fda.gov/downloads/ advisorycommittees/committeesmeetingmaterials/drugs/ peripheralandcentralnervoussystemdrugsadvisorycommittee/ ucm247490.pdf. Accessed October 23, 2015.

10. Wechsler RT, Li G, French J, et al. Conversion to lacosamide monotherapy in the treatment of focal epilepsy: results from a historical-controlled, multicenter, doubleblind study. Epilepsia 2014;55:1088-1099.

11. Fisher RS, Acevedo C, Arzimanoglou A, et al. A practical clinical definition of epilepsy. Epilepsia 2014;55: 475-482.

\section{BIG DATA FOR NEUROLOGY. BIG DEAL FOR YOU!}

\section{Neurology Compensation and Productivity Survey and Report}

We're crunching the numbers to help improve neurology practices. Give us your data by April 30, and we will give you the survey results this summer-for FREE!

We need your practice data to identify neurology-specific trends and best practices. You need the report to improve your practice efficiencies and better understand your compensation and market value. Complete the survey by April 30 to receive the 2016 Neurology Compensation and Productivity Report and online customizable results dashboard for FREE-a \$600 value!

Learn more at AAN.com/view/2016NeuroSurvey. 


\section{Neurology}

Conversion to eslicarbazepine acetate monotherapy: A pooled analysis of 2 phase III studies

Michael R. Sperling, Jacqueline French, Mercedes P. Jacobson, et al.

Neurology 2016;86;1095-1102 Published Online before print February 24, 2016

DOI 10.1212/WNL.0000000000002497

This information is current as of February 24, 2016

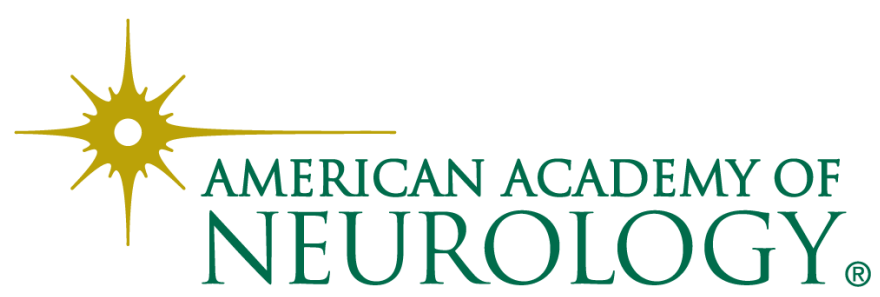




\section{Updated Information \& Services}

\section{Supplementary Material}

\section{References}

Subspecialty Collections

\section{Permissions \& Licensing}

\section{Reprints}

including high resolution figures, can be found at: http://n.neurology.org/content/86/12/1095.full

Supplementary material can be found at: http://n.neurology.org/content/suppl/2016/02/24/WNL.0000000000002 497.DC1 http://n.neurology.org/content/suppl/2016/02/24/WNL.0000000000002 497.DC2

This article cites 9 articles, 0 of which you can access for free at: http://n.neurology.org/content/86/12/1095.full\#ref-list-1

This article, along with others on similar topics, appears in the following collection(s):

All Epilepsy/Seizures

http://n.neurology.org/cgi/collection/all_epilepsy_seizures Antiepileptic drugs

http://n.neurology.org/cgi/collection/antiepileptic_drugs Clinical trials Randomized controlled (CONSORT agreement) $\mathrm{http} / / / \mathrm{n}$.neurology.org/cgi/collection/clinical_trials_randomized_control led_consort_agreement

Partial seizures

http://n.neurology.org/cgi/collection/partial_seizures

Patient safety

http://n.neurology.org/cgi/collection/patient_safety

Information about reproducing this article in parts (figures,tables) or in its entirety can be found online at:

http://www.neurology.org/about/about_the_journal\#permissions

Information about ordering reprints can be found online:

http://n.neurology.org/subscribers/advertise

Neurology ${ }^{\circledR}$ is the official journal of the American Academy of Neurology. Published continuously since 1951 , it is now a weekly with 48 issues per year. Copyright @ 2016 American Academy of Neurology. All rights reserved. Print ISSN: 0028-3878. Online ISSN: 1526-632X.

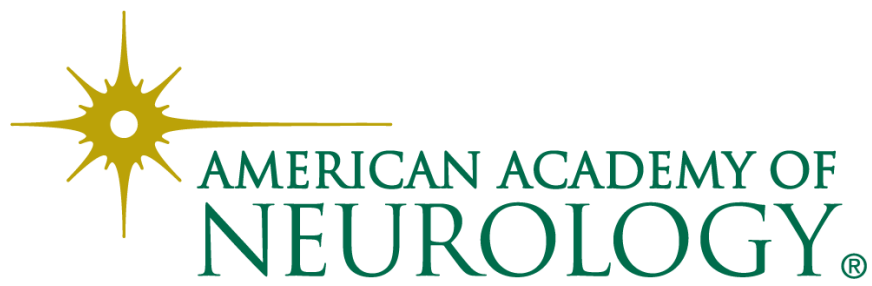

